\title{
Expression of circulating annexin A2 in hepatic diseases and hepatocellular carcinoma
}

\author{
Ebtesam El-Gezawy', Laila Abdelbaki², Mohamed Zeinel Deen ${ }^{3}$, Sahar Eldeek ${ }^{4}$ and Marwa I. Abdelgawad ${ }^{5^{*}}$
}

*Correspondence: esmailmarwa@yahoo.com

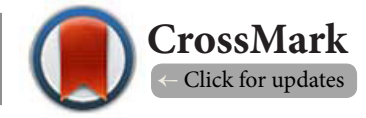

\author{
'Department of Clinical Pathology, Faculty of Medicine, Assiut University, Egypt. \\ ${ }^{2}$ Department of Tropical Medicine and Gastroenterology, Faculty of Medicine, Assiut University, Egypt. \\ ${ }^{3}$ Department of Internal Medicine, Faculty of Medicine, Assiut University, Egypt. \\ ${ }^{4}$ Department of Biochemistry, Faculty of Medicine, Assiut University, Egypt. \\ ${ }^{5}$ Department of Clinical Oncology, Faculty of Medicine, Assiut University, Egypt.
}

\begin{abstract}
Background and objectives: Hepatocellular carcinoma (HCC) is the fifth most common malignancy and the third leading cause of cancer related mortality worldwide. The identification of new high-sensitivity and high-specificity markers for HCCis essential. Annexin A2 (ANXA2) plays an important role in the pathogenesis of multiple malignancies particularly HCCs and its expression strongly also affects the outcomes of HCC patients. This study aimed to investigate the clinical utility of hepatic and circulating Annexin A2 expression levels as a novel diagnostic marker of $\mathrm{HCC}$ and to correlate its level with alpha fetoprotein (AFP), the current marker ofHCC.

Patients and methods: A total number of 40 patients( 6 patients with chronic hepatitis, 8 patients with liver fiberosis, 6 patients with liver cirrhosis, 8 patients with early HCC and 12 patients with late HCC). The same number of age and sex matched healthy people was enrolled as a control group. All patients and controls were subjected to full medical history, complete medical examination abdominal sonography, laboratory investigations including liver function tests, AFP, platelet count, Prothrombin time and concentration, HBsAg, anti-HCV and serum HCV RNA quantitation by real time PCR. Liver biopsies were done for all patients. Evaluation of serum ANXA2 level for all patient and controlgroups was detected by using a human ANXA2 ELISA kit. Analyzing the ANXA2 expression at mRNA and protein levels was detected for patient groups by using RT- PCR by immunohistochemistry staining, respectively. Results: Serum ANXA2was significantly increased in all patient groups (except for chronic hepatitis group) compared to the control group $(\mathrm{P}<0.01)$. The serological evaluation and expression of ANXA2 levels were significantly increased in early HCC compared to serum AFP. ANXA2 expression was localized in both cell membrane and cytoplasm in HCC tissue, not detected in normal tissues and limited to some hepatocytes in chronic hepatitis patients. Over expression of ANXA2 mRNA levelwas present in $\mathrm{HCC}$ tissues compared to other patient groups $(\mathrm{P}<0.001)$. There was a significant relation with $\mathrm{HCV}$ infection, $(\mathrm{P}<0.001)$ when comparing ANXA2 values among positive and negative HCV RNA in HCC patients. No correlations were found between serum ANXA2 levels with serum AST,ALT, platelet count, INR and HBsAgin comparison to controls.

Conclusion: Our results demonstrated increased levels of ANXA2 in both of tissues and sera of HCC patients and also in both AFP-positive and -negative cases. Results of serumANXA2 was concomitant with hepatic ANXA2 expression by RT-PCR and immunocytochemistry staining. Remarkably, Combination of conventional serum marker AFP with serumANXA2 may complement and benefit for early HCC detection.
\end{abstract}

Keywords: Annexin A2, hepatocellular carcinoma, alpha-fetoprotein 


\section{Introduction}

Hepatocellular carcinoma (HCC) is the fifth most common malignancy and the third leading cause of cancerrelated mortality worldwide. Chronic viral hepatitis is a major risk factor for hepatocellular carcinoma as hepatitis B virus (HBV)or hepatitis $\mathrm{C}$ virus ( $\mathrm{HCV})$. They induced liver cirrhosis which is risk factors for HCC as $>80 \%$ of HCCs feature a history of cirrhosis. Therefore, cirrhosis is considered the premalignant condition of HCC [17].

In Egypt, the growing incidence of HCC, which is nearly doubled over the last decade [4] is parallel with that Egypt are plugged with highest prevalence of $\mathrm{HCV}$ in the world, ranging from 6 to $28 \%$ [22]. Although $\mathrm{HBV}$ is considered worldwide as a major risk factor for liver cirrhosis and HCC, the prevalence of HBV infection in Egypt has been declining over the last two decades [12].

Early HCC patients lacked of effective diagnostic and screening strategies, most patients present with overt advanced stage of the disease. Currently, the most utilized surveillance laboratory markers for patients with cirrhosis are serum alpha-fetoprotein (AFP) level and ultrasonography with some limits [19]. There is about 30\% HCC cases with normal serum AFP levels are hardly diagnosed before any clinical manifestations appear, so, AFP is limited, not efficient and have low sensitivity and specificity, particularly during the early stages of HCC [18,31]. Therefore, it highlights the need for new early detection biomarkers for HCC [27].

Annexin A2, is a $36 \mathrm{kDa}$ calcium-binding cytoskeletal protein which is localized at the extracellular surface of endothelial cells and various types of tumor cells [1]. The increased expression of ANXA2 has been reported in cancers of the breast, liver, prostate, pancreas and ovary [20].

Regarding normal liver tissue, It was shown that ANXA2 is consistently negative in hepatocytes but expressed in the biliary epithelial cells and endothelial cells [2,7]. During hepatocarcino -genesis, ANXA2 is expressed in limited hepatocytes of cirrhotic liver tissues and obviously elevated in the malignant hepatocytes [29]. Moreover, ANXA2 is up regulated in HCC tissues at the messenger RNA and protein levels [13]. Adding ANXA2 to the established histological diagnostic marker panel has been considered to improve the diagnostic accuracy in HCC. In addition, serum ANXA2 concentrations were frequently elevated in HCC patients [16].

It was shown that ANXA2 plays an important role in the hepatocyte malignant transformation and HCC development. So it may be used as a serological marker for HCC to enable early diagnosis. It is reported that ANXA2 expression is up regulated in HCC compared with benign liver disease [7].

This study was to evaluate the value of serum ANXA2 levels as non-invasive tool in correlation with ANXA2 expression and histopathology of the liver biopsy in prediction of hepatic diseases and hepatocellular carcinoma. The second issue is to prove the concept that serum levels of ANXA2 are also elevated in early stage HCC patients who has low AFP levels, a widely used liver cancer marker.

\section{Materials and methods Study population}

This study included a total of 40 patients who were recruited from the outpatient clinics of the Tropical, Internal Medicine and Clinical Oncology departments, Assiut University Hospitals from January 2013 till April 2014). They were 11males (27.5\%) and 29 females $(72.5 \%)$ with age ranged between (29-81 years) with Mean \pm SD $(57.73 \pm 12.45)$. The same number of age and sex matched healthy people as a control group with negative hepatitis viral markers [HBV surface antigen, and anti-hepatitis $\mathrm{C}$ virus (HCV)], a normal alanine aminotransferase level and normal Abdominal ultrasonography obtained from the Central Blood Transfusion Services(CBTS), Assiut University Hospital, were enrolled in this study.

\section{Study design}

A questionnaire was taken from the patients concerning symptoms and risk factors of liver diseases and HCC. They are classified as follows (6 patients (15\%) with chronic hepatitis c (chronic HCV), 8 patients (20\%) with liver fibrosis, 6 patients (15\%) with liver cirrhosis, 8 patients (20\%) with early HCC and 12 patients (30\%) with late HCC.

All patients and controls were subjected to full medical history, complete medical examination, abdominal sonography, laboratory investigations including: A liver panel, which included platelets count (Plt) (using Cell Dyne 3500 automated cellcounter), Prothrombin time, concentration and international normalized ratio (INR)(using Sysmex CA -1500-Siemens) and liver function tests including total and direct bilirubin, alanine aminotransferase (ALT), aspartate aminotransferase (AST), alkaline phosphatase (ALP), albumin and total proteins was obtained in all patients using (BM Hitachi 911 Chemistry Analyzer). Alpha fetoprotein (AFP) (was measured by Chemiluminescence using (Immulite1000, a kit supplied by Siemens), HBsAg, anti-HCV (ABOTT AXSYM automated immunoassay analyzer) and serum HCV RNA quantitation by real time PCR using (Applied Biosystems 7500 Fast Real-Time PCR System, CA, USA).

\section{Blood samples}

$(5 \mathrm{~mL})$ were collected in the morning and sera separated immediately by centrifugation at $1000 \times \mathrm{g}$ (or 3000rpm) for 15 $\mathrm{min}$ at room temperature. Isolated serum samples were kept at $-80^{\circ} \mathrm{C}$ until analysis.

\section{Detection of annexin A2 (ANXA2) level}

In human serum for all studied groups was detected by using a human ANXA2 enzyme-linked immunosorbent assay(ELISA) kit (Glory Science Co., Ltd., USA) according to the manufacturer's instructions. $40 \mu \mathrm{l}$ of samples or standards was added to monoclonal antibody enzyme well which is pre-coated with human ANXA2 monoclonal antibody, then $10 \mu \mathrm{l}$ of ANXA2 antibodies 
labeled with biotin was added to each well. After that, $50 \mu \mathrm{l}$ of streptavidin-HRP was added to form immune complex, then incubation for 60 minutes was carried out at $37^{\circ} \mathrm{C}$. Washing to remove the uncombined enzyme was performed. Then $50 \mu \mathrm{l}$ of chromogen solution $\mathrm{A}$, and $50 \mu \mathrm{l}$ of chromagen solution $\mathrm{B}$ was added and incubation for 10 minutes was carried out. Finally, $50 \mu \mathrm{L}$ of stop solution was added to each well, and absorbance was read at $450 \mathrm{~nm}$. Calculation was done by using standard curve linear regression equation. The optimal cutoffs were determined using the maximum sum of sensitivity and specificity.

\section{Liver specimens}

For each patient, liver biopsy was taken after making sure that there are no contraindications for biopsy. Liver specimens were washed with PBS solution. Liver biopsy was done for proving the diagnosis of hepatocellular carcinoma. Ultrasound guided core needle biopsies were obtained from the hepatic tumors and immediately fixed in $10 \%$ formalin and sent to the pathologist for histopathological examination. The tumor was graded as well differentiated HCC (grade I), moderately differentiated (grade II) and poorly differentiated (grade III-IV) according to the criteria of the International Working Party [10]. Our research depended on histological evidence through liver biopsy as a golden standard test to confirm the diagnosis of all HCC patients. Early stage of HCC were defined as BCLC (Barcelona Clinic Liver Cancer staging ) stage 0 and $\mathrm{A}$, and late stage was defined as combination of BCLC stage B and stage $C$ [15]. Specimens were stored at $-70^{\circ} \mathrm{C}$.

\section{Reverse transcriptase-polymerase chain reaction (RT-PCR)}

Total RNA extraction from tissue was performed by the kit supplied by QIAGEN (QIAGEN Germany, Lot No. 11252356). Reverse transcription of RNA into complementary DNA (cDNA) was carried out using The Maxima First Strand cDNA Synthesis Kit (Lot no: 142342805) following the manufacture's instructions. The kit uses Maxima Reverse Transcriptase , an advanced enzyme derived in vitro. The Maxima First Strand cDNA Synthesis kit is capable of reproducing cDNA synthesis from a wide range of starting total RNA amounts ( $1 \mathrm{pg}-5 \mu \mathrm{g})$ at elevated temperature $\left(50^{\circ} \mathrm{C}-65^{\circ} \mathrm{C}\right)$ in $15-30$ minutes. Following the reverse transcription, the resultant cDNA was subjected to RT-nested PCR-based amplification that was done by there agent supplied by (Promega).

ANXA2 primers were as follows: forward, 5'-TGAGCGGGATGCTTTGAAC-3', and; reverse, 5'-ATCCTGTCTCTGTGCATTGCTG-3'.

PCRAmplifications were performed in a total of $50 \mu \mathrm{l}$ consisting of $2 \mu \mathrm{l}$ template cDNA, and $48 \mu \mathrm{l} \mathrm{PCR}$ master mix containing 10 mMTris- $\mathrm{HCl}$ (pH 8.3), 25 mM MgCl2, 10 mMd NTP, 100 units Taq DNA polymerase and $0.1 \mu \mathrm{M}$ of each primer. The optimized PCR cycling conditions were as follows: $5 \mathrm{~min}$ at $95^{\circ} \mathrm{C}$ initial denaturation, followed by 25 cycles of denaturation at $95^{\circ} \mathrm{C}$ for $30 \mathrm{sec}$, Combined annealing at $55^{\circ} \mathrm{C}$ for $30 \mathrm{sec}$ and primer extension at $72^{\circ} \mathrm{C}$ for $30 \mathrm{sec}$.

\section{Detection}

Ten microlitres of the PCR products were analyzed by electrophoresis on $2 \%$ agarose gelsin TAE buffer, stained by ethidium bromide, and viewed under UV light and analyzed using a digital image analysis system. The expression of DNA was described as positive bands which were detected in comparison to PCR ladder.

Clinicopathological characteristics of circulating ANXA2 expression were analyzed, and its diagnostic efficiency and clinical values in HCC were evaluated by anti-annexin A2 antibody (human ANXA2 antibody, R\&D Systems, USA) by using the steps of Immunostain kit according to the manufacturer's instructions. ANXA2 staining was assessed using the immunoreactive score.

Immunohistochemical staining for ANXA2was performed by(streptavidin-peroxidase method) with anti-human ANXA2 antibody (1:500). Deparaffinized $4 \mu \mathrm{m}$ thick liver sections were washed three times with phosphate buffered solution (PBS) $(\mathrm{pH}$ 7.4), incubated in endogenous peroxidase blocking solution (Immunostain Kit, Biotech, USA), and then treated with 0.01 $\mathrm{mol} / \mathrm{L}$ citrate buffer $\mathrm{pH} 6.0$ for $10 \mathrm{~min}$. Non-specific-antibody binding was blocked by pretreatment with PBS containing $0.5 \%$ bovine serum albumin. Sections were then rinsed in PBS and incubated overnight at $4^{\circ} \mathrm{C}$ with diluted anti-human ANXA2 antibody (1:500) followed by three washes in PBS containing $0.05 \%$ Tween-20. and incubated for $5 \mathrm{~min}$. with steptavidin peroxidase at room temperature. The sections were then washed three times with PBS, and diaminibenzidine was applied for 5 min at room temperature. The slide was rinsed with distilled water, counterstained with Mayer's hematoxylin, dehydrated, air dried, and mounted. The negative control slides were treated with nonspecific mouse IgG. The sections were examined under light microscopy.

ANXA2 staining was assessed using the immune reactive score. In detail, the percentage of positive cells was assessed semi quantitatively and classified as follows: diffuse positive staining $(+++)$ of more than $50 \%$ of total cells; moderate staining $(++), 16 \%-50 \%$; weak staining $(+), 5 \%-15 \%$; and negative staining $(-),<5 \%[\mathbf{2 1}]$.

\section{Statistical analysis}

Statistical analyses were conducted on data collected using SPSS" ver. 17" Chicago. USA. Categorical data are presented as a number and percentage, while continuous data are presented as the mean and standard deviation. Chi- Squared test was used to determine significance for categorical data and continuous data were compared with the Student's ttest or MannWhitney test to determine significance for numeric variables. Person's correlation was used for correlations between groups. The optimal cutoffs were determined using the maximum sum of sensitivity and specificity. The cutoff value selected according to characteristic curves. $\mathrm{P}<0.05$ was considered to indicate a statistically significant. 


\section{Results}

Serum levels of annexin A2 and AFP in HCC patients compared to other patient groups and healthy controls

Serum ANXA2 was measured in healthy controls $(n=40)$ and patients with chronic hepatitis c virus $(n=6)$, patient with liver fiberosis $(n=8)$, posthepatitic cirrhosis $(n=6)$ and patients with HCC ( $n=20)$, including 8 early stage and 12 late stage patients. The ANXA2 levels were significantly higher in all patient groups compared to the control group $(\mathrm{P}<0.05)$ with exception for the chronic hepatitis patient group that showed no significant difference compared to the control group $(\mathrm{P}=0.583)$. Regarding the HCC patient group, there is a highly significant increased ANXA2 compared with the studied groups $(P<0.0001)$. Importantly, it was elevated in the early stage HCC compared with healthy, hepatitis, fibrosis and cirrhosis $(P<0.0001)$ (Table 1 and Figure 1$)$. On the other hand, Serum AFP were significantly higher in the HCC patients compared with the studied groups $(P<0.0001)$ (Table 1 and Figure 1). The patients with hepatitis, fibrosis and cirrhosis backgrounds also had higher serum AFP compared with the control group $(P<0.0001)$. However, AFP levels for early stage HCC were not increased in the same manner as late HCC $(P<0.001))$. There was a similarity and no significant difference between early HCC and the cirrhotic patient groups $(\mathrm{P}=0.567)$ although there is still a significant difference in comparison to the control group $\left(\mathrm{P}<0.001^{\star *}\right)$.

\section{Annexin A2 and AFP as complementary tumor markers}

The sensitivity and specificity of AFP alone in late HCC group (optimal cutoff of $5.96 \mathrm{IU} / \mathrm{ml}$ ) were $73.71 \%$ and $68.43 \%$, respectively. On the other hand, those of ANXA2 (optimal cutoff value of $24.99 \mathrm{ng} / \mathrm{ml}$ ) were $84.32 \%$ and $92.34 \%$ whereas those of the combination of ANXA2 and AFP were $94.32 \%$ and $79.30 \%$. For early stage HCC, the sensitivity and specificity of ANXA2

Table 1. Serum Annexin A2 (ANXA2) and Alpha fetoprotein (AFA) in different studied groups compared to the healthy control group.

\begin{tabular}{|c|c|c|c|}
\hline \multicolumn{4}{|c|}{ ANXA2 } \\
\hline Group & $\mathbf{n}$ & $\mathrm{ng} / \mathrm{ml}$ & P-value \\
\hline Control & 40 & $10.67 \pm 2.89$ & -- \\
\hline Chronic hepatitis & 6 & $11.78 \pm 1.40$ & $\mathrm{P}=0.583$ \\
\hline Fibrosis & 8 & $16.34 \pm 3.96$ & $\mathrm{P}<0.03^{\star}$ \\
\hline Cirrhosis & 6 & $18.45 \pm 3.27$ & $\mathrm{P}<0.04^{*}$ \\
\hline Early HCC & 8 & $33.85 \pm 3.59$ & $\mathrm{P}<0.000^{* * *}$ \\
\hline Late HCC & 12 & $36.89 \pm 5.22$ & $\mathrm{P}<0.000^{* * *}$ \\
\hline \multicolumn{4}{|c|}{ AFP } \\
\hline Group & $\mathbf{n}$ & IU $/ \mathbf{m l}$ & P-value \\
\hline Control & 40 & $4.02 \pm 0.97$ & -- \\
\hline Chronichepatitis & 6 & $17.45 \pm 2.33$ & $\mathrm{P}<0.02^{*}$ \\
\hline Fibrosis & 8 & $21.65 \pm 4.65$ & $\mathrm{P}<0.001^{\star *}$ \\
\hline Cirrhosis & 6 & $37.45 \pm 2.92$ & $\mathrm{P}<0.001^{\star *}$ \\
\hline Early HCC & 8 & $39.34 \pm 4.57$ & $\mathrm{P}<0.001^{\star *}$ \\
\hline Late HCC & 12 & $320.23 \pm 13.68$ & $\mathrm{P}<0.000^{* * *}$ \\
\hline
\end{tabular}

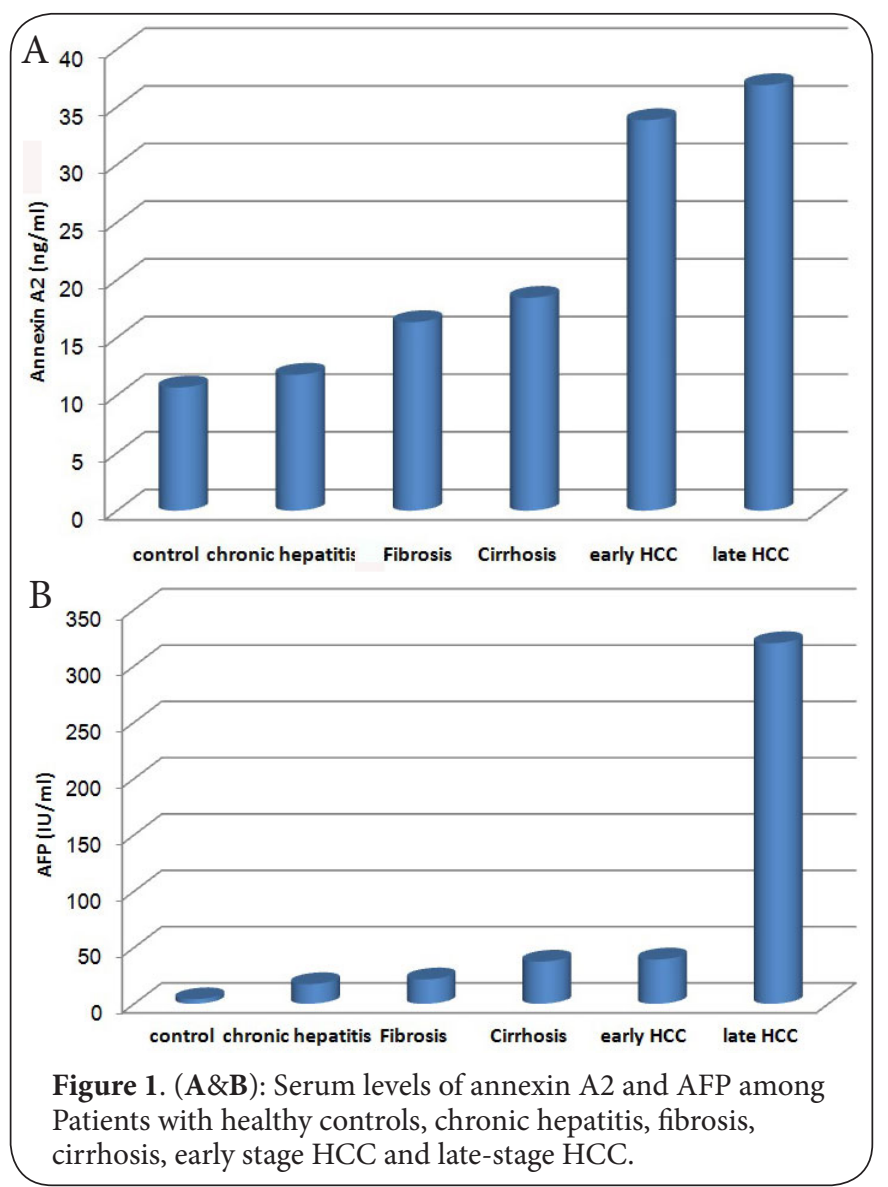

were $79.34 \%$ and $85.56 \%$ respectively, and those of AFP were $67.78 \%$ and $59.85 \%$ respectively. The combination of ANXA2 and AFP improved the sensitivity and specificity for early stage HCC to $80.79 \%$ and $68.43 \%$ respectively (Table 2 ). The correlation coefficient between serum ANXA2 and AFP values was not significant $(P=0.645)$, indicating that measuring both markers in serum can improve the reciprocally diagnostic value.

\section{Relation of circulating Annexin A2 to clinical and serological finding in HCC group}

There was no significant relation between serum annexin A2 and age, gender, serum ALT, INR, platelet count and hepatitis $\mathrm{B}$ infection(HBsAg) (Table 3). However there was a significant relation with hepatitis $\mathrm{C}$ infection $(\mathrm{HCV}),(P<0.001)$ when

Table 2. The sensitivity and specificity of ANXA2 and/or AFP levels in early and late hepatocellular carcinoma patient groups.

\begin{tabular}{lllll}
\hline Parameter & Group & ANXA2 \% & AFP \% & Both \% \\
\hline Sensitivity & Early HCC & $79.34 \%$ & $67.78 \%$ & $80.79 \%$ \\
& Late HCC & 84.32 & $73.71 \%$ & $94.32 \%$ \\
\hline Specificity & Early HCC & 85.56 & $59.85 \%$ & $68.43 \%$ \\
& Late HCC & 92.34 & $68.43 \%$ & $79.30 \%$ \\
\hline
\end{tabular}


Abdelgawad et al. Journal of Cancer Therapeutics \& Research 2018, http://www.hoajonline.com/journals/pdf/2049-7962-6-2.pdf

Table 3. Relation of Serum Annexin A2 (mean \pm SD) with clinical and serological parameters in hepatocellular carcinoma group $(\mathrm{n}=20)$.

\begin{tabular}{lllll}
\hline Parameter & Character & N/\% & $\begin{array}{l}\text { Annexin } \\
(\mathbf{n g} / \mathbf{m l})\end{array}$ & $P$-value \\
\hline Sex & Male & $9(45 \%)$ & $33.85 \pm 3.59$ & 0.385 \\
& Female & $11(55 \%)$ & $33.51 \pm 5.33$ & \\
\hline Age & $<50$ years & $6(30 \%)$ & $24.81 \pm 4.55$ & 0.734 \\
& $\geq 50$ years & $14(70 \%)$ & $23.9 \pm 4.56$ & \\
\hline Serum ALT (U/L) & $<80$ & $5(25 \%)$ & $24.44 \pm 5.12$ & 0.862 \\
& $\geq 80$ & $15(75 \%)$ & $24.24 \pm 5.54$ & \\
\hline Albumin, g/dL & $<3$ & $12(60 \%)$ & $31.23 \pm 5.21$ & 0.758 \\
& $\geq 3$ & $8(40 \%)$ & $31.48 \pm 4.11$ & \\
\hline Platelets (x10 $/ \mathrm{L})$ & $<40$ & $7(35 \%)$ & $36.98 \pm 3.34$ & 0.51 \\
& $\geq 40$ & $13(65 \%)$ & $35.99 \pm 3.23$ & \\
\hline HBsAg & Positive & $2(10 \%)$ & $32.2 \pm 2.5$ & 0.52 \\
& Negative & $18(90 \%)$ & $31.45 \pm 5.1$ & \\
\hline HCV RNA & Positive & $17(85 \%)$ & $36.89 \pm 5.22$ & $<0.001^{* *}$ \\
& Negative & $3(15 \%)$ & $27.11 \pm 6.2$ & \\
\hline AFP (IU/ml) & $<50$ & $5(25 \%)$ & $24.60 \pm 7.60$ & 0.685 \\
& $\geq 50$ & $15(75 \%)$ & $24.22 \pm 9.15$ & \\
\hline Tumour size Cm & $<5$ & $11(55 \%)$ & $24.14 \pm 5.78$ & $0.000^{* * *}$ \\
& $\geq 5$ & $9(45 \%)$ & $36.11 \pm 5.23$ & \\
\hline TNM Staging & Stages I-II & $13(65 \%)$ & $26.19 \pm 5.31$ & $0.001^{* *}$ \\
& Stages III-IV & $7(35 \%)$ & $36.67 \pm 4.11$ & \\
\hline
\end{tabular}

comparing ANXA2 values among positive and negative HCV RNA. Serum ANXA2 levels was dramatically higher with Stage III and IV compared with stage I and II TNM staging and also significantly higher with increase tumour size $(>3 \mathrm{~cm}$ in diameter) $(P<0.001)$. ANXA2 levels were also significantly higher in patients with moderately and poorly differentiated HCC as compared with well-differentiated HCC $(P<0.0001)$.

AnnexinA2 mRNA expression level in HCC tissues ANXA2 mRNA levels were detected in in all patient groups. The ANXA2 mRNA over expression level was obviously and significantly higher in HCC tissues rather than in the other patient groups $(P<0.001)$. ANXA2 expression was detected in all HCC patient group (20/20,100\%), (Table 4, Figures 2A and 2B). Comparing with HCC ANXA2 over expression bands at 36 $\mathrm{KDa}$, there were moderate expressions regarding the intensity of the bands in fibrotic and cirrhotic patient groups. A very weak band was detected at in chronic hepatitis $(\mathrm{CH})$ patients.

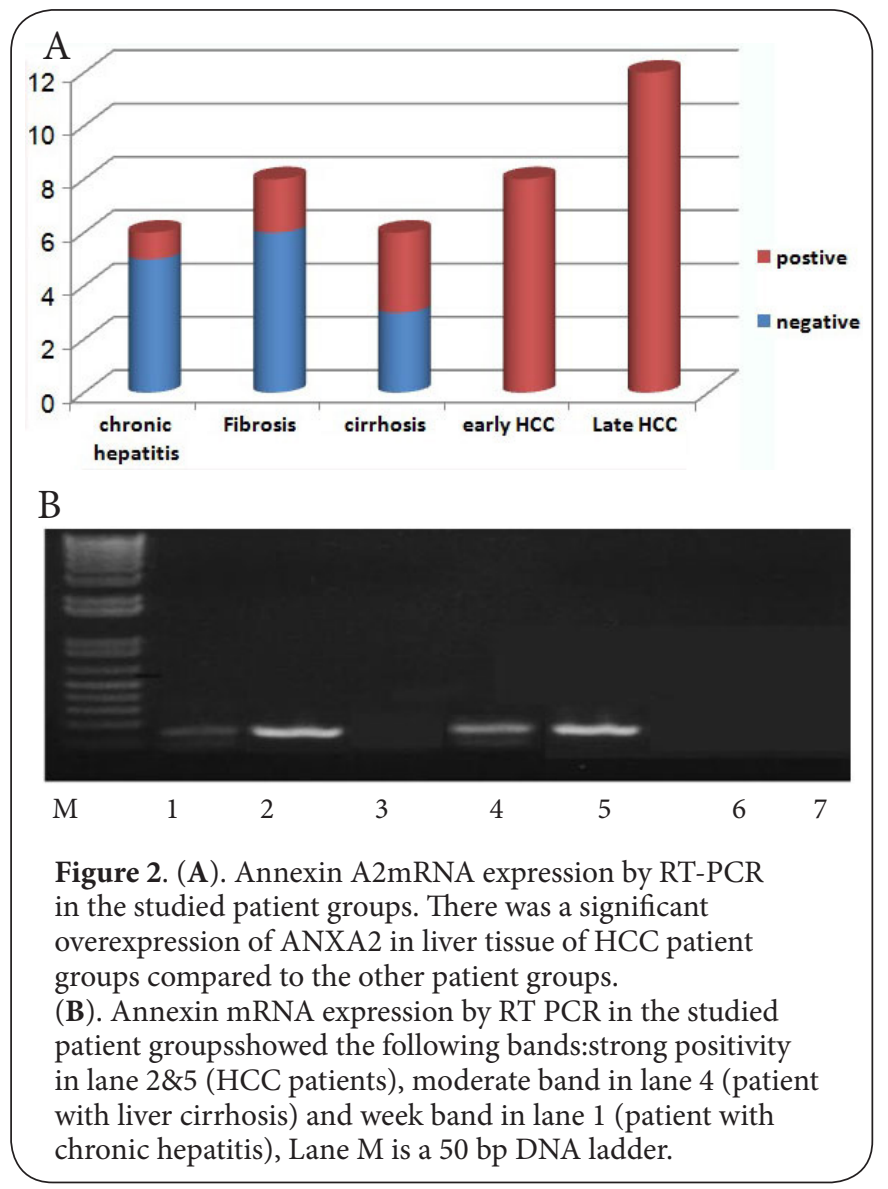

\section{Immunohistochemistry of hepatic annexin A2 expression and distribution}

The intensity and comparative analysis of ANXA2 expression in different liver tissues are shown in (Table 4, Figures 3 and $\mathbf{4}$ ). ANXA2 expression was not detected in normal liver tissue $(0 / 40,0 \%)$ while it was seen in some hepatocytes of chronic hepatitis tissue $(1 / 6,16.66 \%)$, fibrotic tissue $(2 / 8,25 \%)$ and cirrhotic liver tissue $(3 / 6,50 \%)$. There is increased ANXA2 expression in early and late HCC $(20 / 20,100 \%)$ compared to the other patient groups. In addition, poorly differentiated tissues were more strongly positive than well differentiated tissues. Localization of ANXA2 was in the cytoplasm and membrane of cancer cells, while no staining was detected in normal hepatocytes.

Table 4. Hepatic annexin A2 mRNA and annexin A2 immunehistochemical study in chronic hepatitis, liver fibrosis, liver cirrhosis, early and late hepatocellular carcinoma.

\begin{tabular}{|c|c|c|c|c|c|c|c|c|}
\hline \multirow[t]{2}{*}{ Group } & \multicolumn{2}{|c|}{$\begin{array}{l}\text { Annexin A2 mRNA } \\
\text { expression by RT-PCR }\end{array}$} & \multirow[t]{2}{*}{$P$-value } & \multicolumn{4}{|c|}{$\begin{array}{l}\text { Annexin A2 intensity by } \\
\text { immunehistochemistry }\end{array}$} & \multirow[t]{2}{*}{$P$-value } \\
\hline & Negative & Positive & & - & + & ++ & +++ & \\
\hline Chronic hepatitis $(n=6)$ & 5 & 1 & & 5 & 1 & 0 & 0 & \\
\hline Liver Fibrosis $(\mathrm{n}=8)$ & 6 & 2 & & 6 & 2 & 0 & 0 & \\
\hline Liver cirrhosis $(\mathrm{n}=6)$ & 3 & 3 & $P<0.000^{* * *}$ & 3 & 2 & 1 & 0 & $P<0.000^{* * *}$ \\
\hline Early HCC $(\mathrm{n}=8)$ & 0 & 8 & & 0 & 2 & 4 & 2 & \\
\hline Late HCC $(n=12)$ & 0 & 12 & & 0 & 0 & 3 & 9 & \\
\hline
\end{tabular}



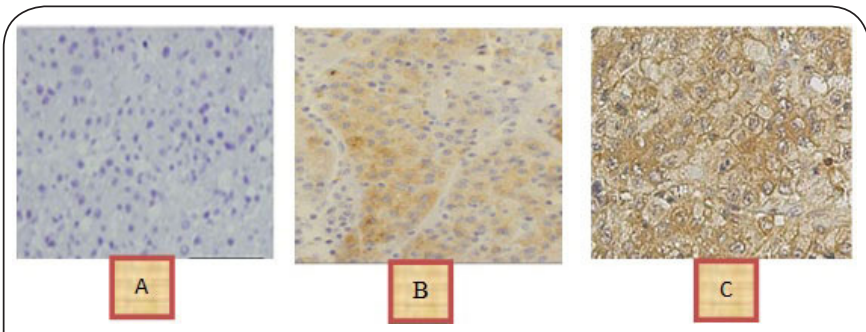

Figure 3. Annexin A2 Immunehistochemical study among liver cirrhosis and HCC patient groups, (A) show negative liver tissue, (B) liver cirrhosis and (C) showed localization of ANXA2 was in the cytoplasm and membrane of HCC cancer cells.

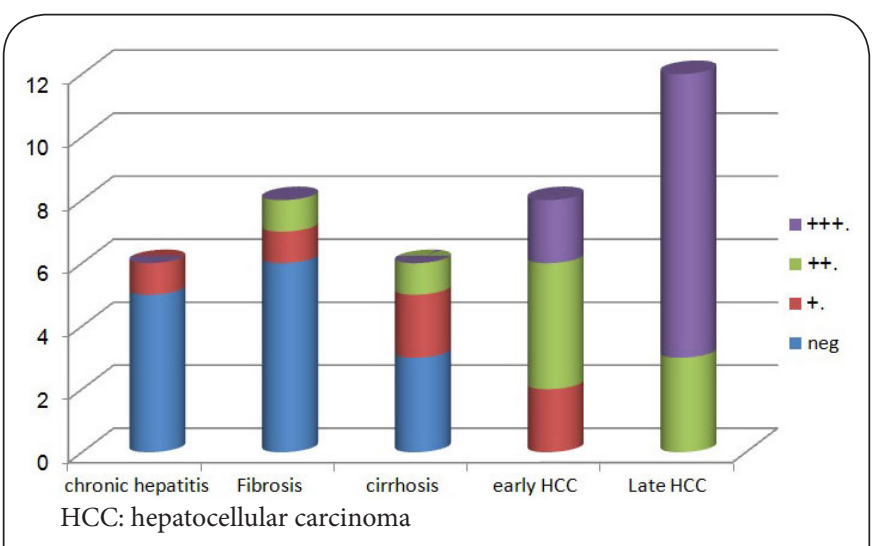

Figure 4. ANXA2 Immunehistochemical study among all the studied patient groups: chronic hepatitis, liver fiberosis, liver cirrhosis, early stage HCC and late-stage HCC patients.

\section{Discussion}

Hepatocellular carcinoma considered to be one of the most malignant tumors, it is the third leading cause of cancer-related death [5]. HCC prognosis is poor, and early detection is of the utmost importance. Although serum AFP is a useful biomarker and has long been used as a marker for the detection and monitoring of HCC, the false-negative results of the AFP level alone may be as high as $40 \%$ in HCC patients with small size tumors $[11,31]$. So, it is not a sensitive or specific diagnostic test for HCC. Annexin A2 is a multifunctional protein, implicated in several membraneassociated processes including fibrinolysis, exocytose is and endocytosis, cellcell adhesion and membranecytoskeletal interaction [25].

Previous reports revealed that high ANXA2 level was reported in HCC and it could be a useful marker for HCC [20]. In this study, the expression of hepatic and circulating ANXA2 was investigated in HCC patients and compared with that in cases of chronic hepatic diseases to explore the clinicopathological characteristics and diagnostic value in HCC and particularly early HCC [32]. Revealed an association between ANXA2 and HCC metastasis but also highlighted a potential therapeutic target for HCC. Our results demonstrated that the analysis of hepatic and serum ANXA2 expression was able to differentiate between the HCC and chronic hepatic diseases including chronic HCV, fibrosis and cirrhotic patients and this is in concomitant with [27]. Although serum AFP considered to be a useful biomarker for the detection and monitoring of HCC, the false-negative rate using the AFP level alone may be high, so, AFP levels have low sensitivity and specificity, particularly during the early stages of cancer $[8,33]$.

[14] study suggests that serum ANXA2 is superior to AFP and a relatively distinct marker for HCC diagnosis. Our results are similar in addition to that ANXA2 can be used as a predictor for early stages HCC diagnosis compared to AFP.

In late HCC group, we reported that the sensitivity and specificity of the combination of AFP and ANXA2 was improved in early and late HCC rather than using each biomarker separately $(80.79 \%$ and $68.43 \%$ for early HCC and $94.32 \%$ and $79.30 \%$ for late HCC). As the correlation coefficient between serum annexin A2 and AFP values was not significant $(P=0.685)$, so it is indicating that measuring both markers in serum can improve the reciprocally diagnostic value. These data were concomitant with previous researches detected that serum annexin A2 has higher sensitivity, specificity and negative predictive value than AFP alone and complementary diagnostic value in combination with AFP for HCC diagnosis as regard sensitivity and negative predictive value [10].

[30], revealed that the sensitivity of serum ANXA2 only was $86.96 \%$, while a combination of ANXA2 with AFP could increase the rate of HCC diagnosis (96.52\%), and the negative predictive value was improved to $96.61 \%$, which is considered more or less similar to our results.

On the other hand, [27] proved that combining both markers notably improved the diagnostic efficiency of early HCC with an achieved sensitivity of $87.4 \%$ and he found that annexin A2 may be an independent serological candidate for HCC, especially in the early stage cases with normal serum AFP.

Recent studies showed the diagnostic role of ANXA2 and follistatin as serum markers for HCC patients and proved that those markers in combination with AFP improved the specificity for HCC diagnosis [3].

The clinicopathologic features of circulating ANXA2 expression in HCC patients demonstrated that there is a very close relationship between ANXA2 level and HCV infection in HCC patient group. Although the mechanisms of hepatocarcinogenesis have not been elucidated, a long-lasting inflammation induced by hepatitis virus infection is a definite risk factor for neoplastic degeneration and the accumulation of genetic alterations [30]. Our results detected there was no significant relationship between the level of ANXA2 and age,sex, serum ALT, platelet count and hepatitis B infection (HBsAg) $(\mathrm{P}>0.05)$ in $\mathrm{Hcc}$ patient group, this result is agreed with [30].

The ANXA2 gene is up regulated in $\mathrm{HBV}$ - and/or $\mathrm{HCV}$ associated HCC [28]. ANXA2 induces cell migration and neoangiogenesis via tissue plasminogen activator-dependent plasmin generation [26], represents metastatic potential [23] 
and promotes invasion and migration of HCC in vitro.

We recorded a significant higher ANXA2 levels with Stage III and IV compared with stage I and II TNM staging and also with increase tumour size and in poorly differentiated compared to well differentiatedtumour. This is agreed with the data of [30] who revealed that there is a significant increased ANXA2 levels with invasion and metastasis.

Regarding hepatic ANXA2 expression at the mRNA level by RT-PCR and protein level by immunohistochemical staining, our study reported that, ANXA2 expression is almost undetectable in normal liver tissue while expression was seen in some hepatocytes in chronic hepatitis tissues, Fibrotic and cirrhotic tissue. The ANXA2 mRNA expression level was obviously, significantly higher and over expressed in HCC tissues rather than in the other patient groups. One explanation showed that its synthesis is induced in transformed hepatocytes [20]. ANXA2 is thought to be involved in the cellular signal transduction associated with inflammation, differentiation andproliferation [24]. Although $[6,30]$, reported that ANXA2 was up-regulatedin HCC, the expression in $\mathrm{CH}$ and liver cirrhosis was not clear, and the phosphorylation of ANXA2 was not studied.

\section{Conclusion}

In conclusion, hepatic ANXA2 expression and elevated circulating ANAX2 levels are associated with hepatocyte malignant transformation of HCC. Therefore, it could be developed as an effective diagnostic and predictive marker for early HCC diagnosis. Our results demonstrated increased levels of ANXA2 in both of tissues and sera of HCC patients. There is no significant difference in using molecular and immunohistochemical staining compared to serum ANXA2 evaluation by ELISA technique so it is recommended to use serum ANXA2 as a simple, noninvasive, accurate and low cost marker in detection of early HCC. Remarkably, Combination of conventional serum marker AFP with serum annexin A2 and may complement and benefit for early HCC detection.

Further validation with a larger sample size may help to systematical evaluation of annexin A2 and develop novel diagnostic and prognostic markers for liver cancer.

\section{Competing interests}

The authors declare that they have no competing interests.

\section{Authors' contributions}

All authors share the following role: Contribution of concept and design of work, collection of samples. Obtaining ethical approval. Performing Lab.work. Data entery and analysis. Interpretation of the results. Writing of the paper and its revision.

\section{Acknowledgement}

We thank Dr Dalia Badary, Lecturer of Pathology department and staff member of the pathology department, Faculty of Medicine, Assiut University for their assistance in experiments, preparation of specimens and their assistance in pathological analysis.

\section{Publication history}

Editor: Kaizhi Lu, Department of Anesthesia,Third Military Medical University, China.

Received: 13 November 2016 Revised: 21 December 2016

Accepted: 13 April 2017 Published: 26 April 2017

\section{References}

1. De Masi S, Tosti ME and Mele A. Screening for hepatocellular carcinoma. Dig Liver Dis. 2005; 37:260-8. | Article | PubMed

2. Dreier R, Schmid KW, Gerke V and Riehemann K. Differential expression of annexins I, II and IV in human tissues: an immunohistochemical study. Histochem Cell Biol. 1998; 110:137-48. I PubMed

3. El-Abd N, Fawzy A, Elbaz T and Hamdy S. Evaluation of annexin A2 and as potential biomarkers for hepatocellular carcinoma. Tumour Biol. 2016; 37:211-6. | Article | PubMed

4. el-Zayadi AR, Badran HM, Barakat EM, Attia Mel D, Shawky S, Mohamed MK, Selim O and Saeid A. Hepatocellular carcinoma in Egypt: a single center study over a decade. World J Gastroenterol. 2005; 11:5193-8. | Article | PubMed Abstract | PubMed FullText

5. Ferlay J, Shin HR, Bray F, Forman D, Mathers C and Parkin DM. Estimates of worldwide burden of cancer in 2008: GLOBOCAN 2008. Int J Cancer. 2010; 127:2893-917. | Article | PubMed

6. Frohlich M, Motte P, Galvin K, Takahashi H, Wands J and Ozturk M. Enhanced expression of the protein kinase substrate p36 in human hepatocellular carcinoma. Mol Cell Biol. 1990; 10:3216-23. | Article | PubMed Abstract | PubMed FullText

7. Gonzalez SA and Keeffe EB. Diagnosis of hepatocellular carcinoma: role of tumor markers and liver biopsy. Clin Liver Dis. 2011; 15:297-306. | Article | PubMed

8. Gerke $V$ and Moss SE. Annexins: from structure to function. Physiol Rev. 2002; 82:331-71. | Article | PubMed

9. Zhu L, Qu XH, Sun YL, Qian YM and Zhao XH. Novel method for extracting exosomes of hepatocellular carcinoma cells. World J Gastroenterol. 2014; 20:6651-7. | Article | PubMed Abstract | PubMed FullText

10. Terminology of nodular hepatocellular lesions. Hepatology. 1995; 22:983-93. | Article | PubMed

11. Lopez JB. Recent developments in the first detection of hepatocellular carcinoma. Clin Biochem Rev. 2005; 26:65-79. | PubMed Abstract | PubMed FullText

12. Khattab MA, Eslam M, Sharwae MA and Hamdy L. Seroprevalence of hepatitis $\mathrm{C}$ and $\mathrm{B}$ among blood donors in Egypt: Minya Governorate, 2000-2008. Am J Infect Control. 2010; 38:640-1. | Article | PubMed

13. Kittaka N, Takemasa I, Takeda Y, Marubashi S, Nagano H, Umeshita K, Dono K, Matsubara K, Matsuura N and Monden M. Molecular mapping of human hepatocellular carcinoma provides deeper biological insight from genomic data. Eur J Cancer. 2008; 44:885-97. | Article | PubMed

14. Lee YL, Ahn BC, Lee Y, Lee SW, Cho JY and Lee J. Targeting of hepatocellular carcinoma with glypican-3-targeting peptide ligand. J Pept Sci. 2011; 17:763-9. | Article | PubMed

15. Llovet JM, Fuster J and Bruix J. The Barcelona approach: diagnosis, staging, and treatment of hepatocellular carcinoma. Liver Transpl. 2004; 10:S115-20. | Article | PubMed

16. Longerich T, Haller MT, Mogler C, Aulmann S, Lohmann V, Schirmacher $\mathrm{P}$ and Brand K. Annexin A2 as a differential diagnostic marker of hepatocellular tumors. Pathol Res Pract. 2011; 207:8-14. | Article | PubMed

17. Madureira PA, Surette AP, Phipps KD, Taboski MA, Miller VA and Waisman $\mathrm{DM}$. The role of the annexin A2 heterotetramer in vascular fibrinolysis. Blood. 2011; 118:4789-97. | Article | PubMed

18. Malaguarnera G, Giordano M, Paladina I, Berretta M, Cappellani A and Malaguarnera M. Serum markers of hepatocellular carcinoma. Dig Dis Sci. 2010; 55:2744-55. | Article | PubMed

19. Marrero JA, Feng Z, Wang Y, Nguyen MH, Befeler AS, Roberts LR, Reddy KR, Harnois D, Llovet JM, Normolle D, Dalhgren J, Chia D, Lok AS, Wagner PD, Srivastava S and Schwartz M. Alpha-fetoprotein, des-gamma carboxyprothrombin, and lectin-bound alpha-fetoprotein in early 
hepatocellular carcinoma. Gastroenterology. 2009; 137:110-8. | Article | PubMed Abstract | PubMed FullText

20. Mohammad HS, Kurokohchi K, Yoneyama H, Tokuda M, Morishita A, Jian G, Shi L, Murota M, Tani J, Kato K, Miyoshi H, Deguchi A, Himoto T, Usuki H, Wakabayashi H, Izuishi K, Suzuki Y, Iwama H, Deguchi K, Uchida $\mathrm{N}$, Sabet EA, Arafa UA, Hassan AT, El-Sayed AA and Masaki T. Annexin A2 expression and phosphorylation are up-regulated in hepatocellular carcinoma. Int J Oncol. 2008; 33:1157-63. | Article | PubMed

21. Nan KJ, Guo H, Ruan ZP, Jing Z and Liu SX. Expression of p57(kip2) and its relationship with clinicopathology, PCNA and p53 in primary hepatocellular carcinoma. World J Gastroenterol. 2005; 11:1237-40. | Article | PubMed Abstract | PubMed FullText

22. National Cancer Registry of Egypt. Magnitude of hepatocellular carcinoma in Egypt. 2010.

23. Ohno Y, Izumi M, Kawamura T, Nishimura T, Mukai K and Tachibana M. Annexin II represents metastatic potential in clear-cell renal cell carcinoma. Br J Cancer. 2009; 101:287-94. | Article | PubMed Abstract | PubMed FullText

24. Singh P. Role of Annexin-II in GI cancers: interaction with gastrins/ progastrins. Cancer Lett. 2007; 252:19-35. | Article | PubMed Abstract PubMed FullText

25. Rescher $U$ and Gerke V. Annexins--unique membrane binding proteins with diverse functions. J Cell Sci. 2004; 117:2631-9. | Article | PubMed

26. Sharma M, Ownbey RT and Sharma MC. Breast cancer cell surface annexin II induces cell migration and neoangiogenesis via tPA dependent plasmin generation. Exp Mol Pathol. 2010; 88:278-86. I Article | PubMed

27. Sun Y, Gao G, Cai J, Wang Y, Qu X, He L, Liu F, Zhang Y, Lin K, Ma S, Yang X, Qian $X$ and Zhao $X$. Annexin A2 is a discriminative serological candidate in early hepatocellular carcinoma. Carcinogenesis. 2013; 34:595-604. I Article | PubMed Abstract | PubMed FullText

28. Yoon SY, Kim JM, Oh JH, Jeon YJ, Lee DS, Kim JH, Choi JY, Ahn BM, Kim S, Yoo HS, Kim YS and Kim NS. Gene expression profiling of human HBVand/or HCV-associated hepatocellular carcinoma cells using expressed sequence tags. Int J Oncol. 2006; 29:315-27. | Article | PubMed

29. Yu GR, Kim SH, Park SH, Cui XD, Xu DY, Yu HC, Cho BH, Yeom YI, Kim SS, Kim SB, Chu IS and Kim DG. Identification of molecular markers for the oncogenic differentiation of hepatocellular carcinoma. Exp Mol Med. 2007; 39:641-52. | Article | PubMed

30. Zhang HJ, Yao DF, Yao M, Huang H, Wu W, Yan MJ, Yan XD and Chen J. Expression characteristics and diagnostic value of annexin $A 2$ in hepatocellular carcinoma. World J Gastroenterol. 2012; 18:5897-904. | Article | PubMed Abstract | PubMed FullText

31. Zhou L, Liu J and Luo F. Serum tumor markers for detection of hepatocellular carcinoma. World J Gastroenterol. 2006; 12:1175-81. | Article | PubMed Abstract | PubMed FullText

32. Dong $Z$, Yao $M$, Zhang $H$, Wang L, Huang $H$, Yan $M$, Wu W and Yao $D$. Inhibition of Annexin A2 gene transcription is a promising molecular target for hepatoma cell proliferation and metastasis. Oncol Lett. 2014 7:28-34. | Article | PubMed Abstract | PubMed FullText

33. Zheng L, Foley K, Huang L, Leubner A, Mo G, Olino K, Edil BH, Mizuma M, Sharma R, Le DT, Anders RA, Illei PB, Van Eyk JE, Maitra A, Laheru D and Jaffee EM. Tyrosine 23 phosphorylation-dependent cell-surface localization of annexin A2 is required for invasion and metastases of pancreatic cancer. PLoS One. 2011; 6:e19390. | Article | PubMed Abstract | PubMed FullText

Citation:
El-Gezawy E, Abdelbaki L, Deen M.Z, Eldeek S and
Abdelgawad M.I. Expression of circulating annexin A2
in hepatic diseases and hepatocellular carcinoma.
J Cancer Ther Res. 2017; 6:2.
http://dx.doi.org/10.7243/2049-7962-6-2

